\title{
Score to predict pain after excisional hemorrhoidectomy
}

\author{
Sim Sai Tin • Viroj Wiwanitkit
}

Accepted: 29 September 2014 / Published online: 11 October 2014

(C) Springer-Verlag Berlin Heidelberg 2014

\section{Dear Editor:}

We would like to discuss on the publication on "score to predict pain after excisional hemorrhoidectomy" [1]. Selvaggi et al. developed a new score and reported that the "score can stratify the risk of EP following EH, identifying high-risk patient candidates to active analgesic administration or alternative surgical procedures" [1]. This work has some weak points. First, there is no complete evaluation of the newly set score compared to the existing score (such as cumulative pain score developed by Althaus et al. [2] or analgesia/nociception index [3]). Second, the scoring system development lacks a completer process on validation and reliability test. The standard study to develop a new score can be seen in some previous reports such as the report of Thabane et al. on the "Development and validation of a risk score for post-infectious irritable bowel syndrome" [4].

\section{References}

1. Selvaggi F, Pellino G, Sciaudone G, Candilio G, Canonico S (2014) Development and validation of a practical score to predict pain after excisional hemorrhoidectomy. Int J Colorectal Dis. doi:10.1007/ s00384-014-1999-3

2. Althaus A, Hinrichs-Rocker A, Chapman R, Arránz Becker O, Lefering R, Simanski C, Weber F, Moser KH, Joppich R, Trojan S, Gutzeit N, Neugebauer E (2012) Development of a risk index for the prediction of chronic post-surgical pain. Eur J Pain 16(6): 901-10

3. Boselli E, Bouvet L, Bégou G, Dabouz R, Davidson J, Deloste JY, Rahali N, Zadam A, Allaouchiche B (2014) Prediction of immediate postoperative pain using the analgesia/nociception index: a prospective observational study. Br J Anaesth 112(4):715-21

4. Thabane M, Simunovic M, Akhtar-Danesh N, Marshall JK (2009) Development and validation of a risk score for post-infectious irritable bowel syndrome. Am J Gastroenterol 104(9):2267-74
S. S. Tin $(\triangle)$

Medical Center, Shantou, China

e-mail: simsaitin@gmail.com

V. Wiwanitkit

Hainan Medical University, Haikou, China 